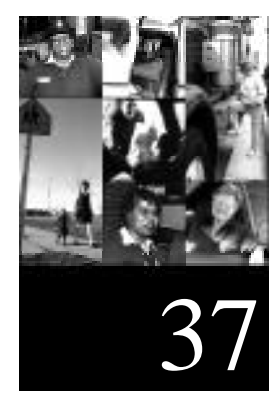

\title{
The Influence of Gender and Occupation on Individual Perceptions of Telecommuting
}

Patricia L. Mokhtarian Michael N. Bagley Lisa Hulse

University of California, Davis

Ilan Salomon

Hebrew University 


\title{
THE INFLUENCE OF GENDER AND OCCUPATION ON INDIVIDUAL PERCEPTIONS OF TELECOMMUTING
}

\begin{abstract}
Accurate forecasts of the adoption and impacts of telecommuting depend on an understanding of what motivates individuals to adopt telecommuting, since those motivations will offer insight into who is likely to telecommute under what circumstances. Motivations for telecommuting are likely to differ by various segments of society. In this study, we analyze gender and occupation differences in the perceptions of telecommuting for 583 employees of the City of San Diego. Numerous differences are identified. Most broadly, women on average rated the advantages of telecommuting more highly than menboth overall and within each occupation group. Women were more likely than men to cite family, personal benefits, and stress reduction as advantages of telecommuting, and more likely to see the lack of visibility to management as a disadvantage. Clerical workers were more likely than managers or professionals to see the family, personal, and office stress-reduction benefits of telecommuting as important, whereas managers and professionals were more likely to cite getting more work done as the most important advantage of telecommuting. Reduced social interaction appeared to be of about equal concern to both clerical and professional/technical workers, and reduced professional interaction was of greatest concern to managers and professionals. Professionals were more likely than the other two job types to see the lack of visibility to management and the need for discipline as disadvantages.
\end{abstract}

\section{INTRODUCTION}

Telecommuting has recently gained recognition as a potentially effective transportation demand management strategy. Reasonable estimates of the travel impacts of telecommuting depend on accurate forecasts of telecommuting adoption by individuals. Accurate forecasts, in turn, depend on an understanding of what motivates individuals to adopt telecommuting, since those motivations will offer insight into who is likely to telecommute under what circumstances. Motivations for telecommuting are likely to differ by various segments of society. Understanding these differences is important for those trying to market telecommuting as a work option or transportation demand management strategy, as well as for those trying to accurately predict future adoption and impacts of telecommuting.

For example, conventional wisdom has suggested that telecommuting would be more attractive to women than men. Since working women still undertake a disproportionate share of domestic responsibilities (Tingey et al., 1996), the hypothesis is that the promise of telecommuting to save time and to offer greater flexibility would appeal even more strongly to women than to men. A previous study of telecommuting adoption (Mokhtarian and Salomon, 1996a) found that indeed, females were significantly more likely to want to telecommute from home than males $(\mathrm{p}=0.00077)$. However, preference within both groups was quite high ( $92 \%$ for women in the sample; $83 \%$ for men), raising the question of whether women and men wanted to telecommute for the same reasons or not.

In the same study, preference for home-based telecommuting did not vary significantly across major occupation groups: $88 \%$ of respondents in each of the manager, professional/technical, and clerical groups wanted to telecommute. Although the proportions of respondents wanting to telecommute are relatively uniform across these groups, the question again may be asked as to whether there are significant differences among them in their reasons for wanting to telecommute-or, for that matter, not want- 
ing to telecommute. For example, concerns that telecommuting would hinder professional development due to a reduction in workplace interaction may be more of a detriment to managers and professionals than to clerical workers (Olson and Primps, 1984).

Identifying differences such as these is the aim of this study. Specifically, we examine whether the perceived advantages and disadvantages of telecommuting differ significantly by gender and occupation. We study six gendered groups: managers, professionals, and clerical workers separated by gender. The remainder of the paper is divided into three sections. The next section describes the data analyzed in the study and the variables created from them, while also presenting some key socioeconomic characteristics of the sample. Section 3 begins by specifying a number of hypothesized gender and/or occupation differences in the perceived advantages and disadvantages of telecommuting. Then, statistical tests of these and other differences are reported. The final section summarizes and discusses the results.

\section{THE RESEARCH CONTEXT}

\section{THE STUDY, THE SAMPLE, AND THE SURVEY}

This study is part of an ongoing research project involving modeling telecommuting preference and choice (see Mokhtarian and Salomon, 1994; 1996a, b, c; Mannering and Mokhtarian, 1995; Bagley, 1995). Although previously-reported models have found attitudinal variables to be important to both preference and choice (Mokhtarian and Salomon, 1996b, c), a systematic examination of how perceptions of telecommuting differ by gender and occupation has not been undertaken by the project before now.

The sample consists of 583 usable responses to a fourteen-page self-administered questionnaire distributed to 1428 employees of the City of San Diego in December 1992. The survey contained questions on previous awareness of and experience with telecommuting, job characteristics, ability to telecommute, advantages and disadvantages of telecommuting, information on other possible choices to satisfy hypothesized lifestyle drives, attitudes toward telecommuting and issues related to lifestyle drives, and sociodemographic characteristics. Mokhtarian and Salomon (1996a) discuss selection bias in the sample and its possible implications for the generalizability of reported findings. For the current study, selection bias means that the proportion of the sample in each study group is not necessarily representative of that group's presence in the population as a whole, but it can be expected that the sample reasonably represents each group's perceptions of telecommuting. That is, female clerical workers, say, may be underrepresented in the sample, but the female clerical workers that are in the sample are likely to be fairly representative of how the population of female clerical workers views telecommuting.

This study focuses on the survey questions relating to the advantages and disadvantages of telecommuting. Respondents were asked to rate on a four point scale (not at all important, slightly important, moderately important, and extremely important) 17 advantages and 11 disadvantages. These characteristics of telecommuting were developed from the literature (e.g. DeSanctis, 1984; Katz, 1987) and from researcher judgment. "Other" advantages and disadvantages could also be specified by the respondent; these were recoded to listed attributes where possible, and otherwise not further analyzed here. After rating the characteristics on each list, respondents were asked to rank the top three advantages and disadvantages, respectively. Respondents were rating each attribute with respect to their perceptions of telecommuting for themselves. Hence, managers' views in particular should be understood to relate to telecommuting for their own situation and not for their staff. 
The 28 intercorrelated attributes were factor analyzed together to reduce them down to nine (oblique) factors (Mokhtarian and Salomon, 1996c). The 17 advantages loaded on five of these factors, which may be viewed as measuring drives or motivations to telecommute, whereas the 11 disadvantages loaded on the other four factors which constitute constraints on the desire and/or ability to telecommute. Tables 1 and 2 display the exact wording of the advantages and disadvantages listed in the survey, and indicate the factor(s) on which each statement loaded most heavily.

Table 1

Advantages of Telecommuting

\begin{tabular}{|c|c|}
\hline Advantage Statement & Factor \\
\hline To have more time for mvself. & Personal Benefits \\
\hline To rechlye the stress of commuting, & Stress \\
\hline To get more work done. & Stress \\
\hline To rechuce the stress I experience in the main office. & Stress, Per sonal Benefits \\
\hline To make it easier to handle dependent (child or addult) care. & Familv \\
\hline To have more independence. & Personal Benefits \\
\hline To spend more time with mv familv. & Familv \\
\hline To save monev. & Personal Benefits \\
\hline To make it easier to pur sue educational or personal inter ests. & Personal Benefits \\
\hline To helo the environment bv driving less. & Stress \\
\hline To have more control over mv phvsical working environment. & Stress, Per sonal Benefits \\
\hline To increase flex ibilitw. & Personal Benefits \\
\hline To be able to work while temporarilv disabled. & Disabilitw/Parental Leave \\
\hline To be able to work while perm anentlv disabled. & Disabilitw/Parental Leave \\
\hline To be able to work instead of taking narental leave. & Familv \\
\hline To keep working at this job after changing mv residence. & Relocation \\
\hline
\end{tabular}

Table 2

Disadvantages of Telecommuting

\begin{tabular}{|c|c|}
\hline Disackrantage Statement & Factor \\
\hline In general I rrefer the scial interction fourd at the conventional workwace. & Workwlace Interaction \\
\hline I mefer the mofessional interaction foumd at the corwentional workalace. & Worknlace Interaction \\
\hline I would be concemed about mur omonturities for visbilitvand career actancement. & Management Wisibility \\
\hline There is a nisk that I would be viewed negativelvbvmanagement. & Management Visibilitv \\
\hline The mainoffice is nicer / better ecruinoed & Office Discinline \\
\hline Its harder to get motivated to work awav from the main office. & Office Discinlire \\
\hline Its too much trouble to nemerrber what to take back and forth between work locations. & Office Discinlire \\
\hline Mvcomrmate trin is a useful tansition between home and work. & Cormute Berefit \\
\hline 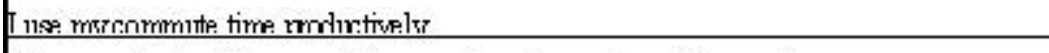 & Conmmite Perefit \\
\hline 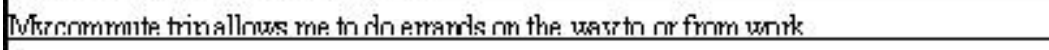 & Conmminte. Perefit \\
\hline Working at home mavincease familwconflicts. & Commute Eerefit \\
\hline
\end{tabular}




\section{DEFINING OCCUPATION CATEGORIES}

Before examining differences by gender and occupation, a brief description of how the occupation categories were defined may be in order, as a reminder of the uncertainties inherent in variable measurement. More than $95 \%$ of the original sample of 628 people had jobs that could be categorized as managerial $(14.5 \%)$, professional $(55.5 \%)$, or clerical $(25.1 \%)$. This result, plus the fact that many other telecommuting research projects have focused on the above three job categories (see e.g., Pratt, 1984; Hartman et al., 1991), were motivations to limit the analysis to these occupations. Unfortunately, occupational categories are not precisely defined in the public mind, and thus, people doing nearly identical jobs may label them very differently. Some people may be more likely to identify with the type of work they do rather than with their work status (i.e., title or rank), and vice versa. It was expected that this would especially be a problem with the manager occupation group. Consequently, we used two questions to classify respondents with respect to manager status. The question, "Whom do you supervise?" had as responses "no one", "one or more staff", and "one or more supervisors"; the question, "Which of the following best describes your occupation?" included responses of "manager/ administration", "professional/ technical", and "clerical/administrative support" among others.

When the responses to these two questions were cross-tabulated, two types of discrepancies arose. Fifteen people classified themselves as manager/administration based on the second question, but responded to the first question that they supervised no one. Conversely, 156 people classified themselves as either professional/technical or clerical, but indicated that they supervised people. The first group of people may have included some with non-supervisory administrative responsibilities and some whose job title may have contained the word "manager" as a courtesy. In neither case would it be desirable to combine that first group with "true" managers, and since there was no way to reclassify them into one of the other two categories they were discarded from the analysis.

Regarding the second type of discrepancy, it is recognized that the terms "manager" and "supervisor" are not universally considered synonymous (Feuer, 1988), and therefore that people may be supervisors without considering themselves to be (or having the title of) managers. Therefore, those people in this group who reported only that they supervised "staff" were not moved, whereas the 28 professional/ technical and three clerical workers who reported supervising "supervisors" were reclassified as managers. This increased the size of the manager group from 58 to a more statistically robust 89 . The results of exploratory analyses using the original self-reported occupational designations did not differ materially from the results reported here.

Table 3 presents the final crosstabulation (after reclassification) of occupation by supervisory status of the 583 respondents retained for this study. 
Table 3

Table 3: Supervisor Status by Occupation

Supervisor Status by Occupation

\begin{tabular}{|l|cc|c||c|}
\hline \multirow{2}{*}{ Sup ervises: } & \multicolumn{2}{|l|}{ Occupation } & \multicolumn{2}{|c|}{ Row Totals } \\
\cline { 2 - 5 } & Manager & Professional & C1erical & 369 \\
\hline \hline N one & $0^{1}$ & 236 & 133 & 146 \\
Staff & 21 & 104 & 21 & 68 \\
\hline Supervisors & 68 & $0^{2}$ & $0^{3}$ & $\mathbf{5 8 3}$ \\
\hline Colum n Totals & 89 & 340 & 154 & \\
\hline
\end{tabular}

1 Fifteen respondents who reported being a m anager but not supervising anyone were disc arded.

2 Twenty-eight professional/technical workers who reported supervising supervisors were reclassified as managers.

3 Three clerical workers who reported supervising supervisors were reclassified as $\mathrm{m}$ anagers.

\section{CHARACTERISTICS OF THE SAMPLE}

A comparison of the six study groups on basic demographic characteristics is important for describing the sample and may offer some basis for interpreting the perceptual differences identified in Section 3. Table 4 summarizes several socio-economic characteristics by gender-job type category. For the continuous variables household size, one-way commute length, vehicles per driver, and years in present occupation, analyses of variance were conducted to simultaneously identify any gender and occupation main and interaction effects. For the remaining (categorical) variables, Pearson chi-square tests were conducted for differences by gender and occupation separately. The p-values of these tests are reported in the final two columns of the table.

Four variables significantly distinguished between both gender and job type: age, education, household income, and years of experience. On average, males were older than females in each occupation category. Similarly, for each job type, men had higher education levels and household incomes than women, with one exception: female clerical workers reported household incomes slightly higher than those of (the small sample of) male clerical workers. Finally, men had (on average, about four) more years of experience in their present occupation than women, with the same exception.

The remaining variables differed significantly on at most one of the two dimensions of gender and job type. Male respondents generally had larger household sizes, more often had children under the age of 6 , and, as discussed in the introduction, less often wanted to telecommute. Occupation differences were observed for presence of children ages 6-16 (with managers having them most often and professionals least often), presence of someone needing special care (occurring most often for the clerical workers), vehicles per driver (with clerical workers having the least at 0.9) and actual telecommuting (with clerical workers least likely to do it and managers most likely to do it). It is perhaps surprising that proportionally 
Table 4

Demographic and Other Characteristics by Gender and Occupation

\begin{tabular}{|c|c|c|c|c|c|c|c|c|c|}
\hline Variable & Indicator & Female 1 & & & Male1 & & & Significance2 & \\
\hline & & $\begin{array}{l}\text { Mungr } \\
N=24\end{array}$ & $\begin{array}{l}\text { ProffN }=14 \\
3\end{array}$ & $\begin{array}{l}\text { ClerN }=14 \\
2\end{array}$ & Mingr $\mathrm{N}=65$ & $\begin{array}{l}\text { ProftN= } 19 \\
7\end{array}$ & Cler $N=12$ & G & 0 \\
\hline Aoe & mean 3 & 39 & 37 & 39 & 43 & 40 & 43 & 0.004 & 0.001 \\
\hline Houkehold Size & mean size & 24 & 24 & $2 \mathrm{~B}$ & 3 & 28 & 31 & $n \cap n 4^{-1}$ & $\mathrm{~N}$ \\
\hline Presence of Children Under 6 & bercent & $13 \%$ & $20 \%$ & $16 \%$ & $23 \%$ & $24 \%$ & $25 \%$ & 0.06 & $\mathrm{~N}$ \\
\hline Presence of Children 6-15 & having & $29 \%$ & $20 \%$ & $26 \%$ & $29 \%$ & $19 \%$ & $17 \mathrm{x}$ & Na & 0.07 \\
\hline Needina Soecial Care & having & $4 \%$ & $0 \%$ & $8 \%$ & $0 \%$ & $5 \%$ & $0 \%$ & $\mathrm{~N}$ & 0.01 \\
\hline Education 4 & categony & 4.8 & 4.5 & 3.1 & 5.1 & 4.6 & 4.2 & D) & L \\
\hline Household Income & mean 3 & $753 \mathrm{~K}$ & $\$ 55 \mathrm{~K}$ & FA1K & $986 \mathrm{~K}$ & $957 \mathrm{~K}$ & FAOK & 0 & 0 \\
\hline Years in Present Occupation & mean & 7.3 & 6.1 & 7.3 & 133 & 9.9 & 6.9 & 0 & 0.006 \\
\hline One-w av Commute Lenath & miles & 102 & 13.7 & 12.4 & 14.1 & 13.1 & 6.7 & H & N \\
\hline Vhiclesper Driver & mean & 1 & 1.1 & 0.9 & 1.1 & 1.1 & 0.9 & N & 0 \\
\hline Prekerence for (Home-based) & percent & $96 \%$ & $94 \%$ & 894 & $83 \%$ & $84 \%$ & 832 & 0.001 & 0.83 \\
\hline Choice of (Home-based) & bercent & $33 \%$ & $18 \%$ & $5 \%$ & $20 \%$ & $10 \%$ & $8 x$ & 0.657 & 0 \\
\hline
\end{tabular}

more managers (24\%) telecommute than professional workers (13\%), but managers presumably have more autonomy than their staff, and may already themselves have been managed remotely to some degree before beginning to telecommute. In any case, it is clear from these data that whatever face-toface interaction is required of managers can often be scheduled in such a way as to make telecommuting possible.

\section{PERCEPTION DIFFERENCES BY GENDER AND OCCUPATION}

\section{HYPOTHESES}

Based on the literature and on the judgement of the authors, a number of gender- and occupation-related differences in the perception of telecommuting are hypothesized. For example, several studies (e.g. Tingey, et al., 1996; Bielby and Bielby, 1988) have indicated that working women still bear a disproportionate share of household responsibilities, and that this dual role is a source of considerable stress. This suggests that women are more likely than men to view telecommuting as a (partial, at least) solution to those types of pressures. Among occupation groups, we hypothesize that clerical workers (who, in our sample as derived from Table 4, have the lowest education levels, the lowest average household incomes, and the highest rate of incidence of dependents needing special care) are more likely to see telecommuting as a solution to stress. (Whether or not telecommuting succeeds as such a solution, is of course another question; several researchers have noted that telecommuting may in fact increase roleconflict and stress, especially for women with child-care responsibilities, or at least not reduce it materially [Olson and Primps, 1984; DuBrin, 1991; Christensen, 1988; Shamir and Salomon, 1985]). Managers in our sample have the largest households, the highest incidence of older children and the second-highest incidence of young children among the three job types, but they also have the highest levels of education and household income. It is expected that the more affluent managers are more likely to balance work and family through hiring domestic help, and hence are less likely to value telecommuting as a solution for these types of pressures. 
In view of the multiple roles undertaken by women, we expect them to value the utility of the commute trip (in terms of serving as a boundary or transition between home and work, the ability to use the commute productively to run errands, and so on [Salomon and Salomon, 1984]) more highly than men. Hence, we hypothesize that women are more likely than men to see the various benefits from commuting as disadvantages of telecommuting.

Olson and Primps (1984) found that males tended to telecommute for work-related reasons such as reducing distractions and improving the work environment, but in their study, gender was apparently heavily confounded with occupation (with professional workers tending to be male and clerical workers almost exclusively female). Since other studies have found that "when job status is controlled, work attitudes and career commitment are not gender-linked" (Pazy et al., 1996, p. 270; Bielby and Bielby, 1989; Lefkowitz, 1994), we hypothesize that the desire to telecommute to get more work done is strictly a function of occupation, and not of gender.

Olson and Primps also found that male professionals cited reduced stress as an advantage of telecommuting, due to "lack of interruptions", "avoidance of office politics", and "elimination of the stress of commuting". We expect at least the first two of those aspects not to be gender-specific (Duxbury, et al., 1987; Newman, 1989). As for occupation effects, we expect that both professionals and clerical workers may experience office stress. We hypothesize that managers are less likely to be concerned about office stress as they have more control over their office environments.

Lack of visibility to management and fears of the impact that might have on career advancement within the organization have been repeatedly identified as perceived drawbacks of telecommuting (e.g. Duxbury, et al., 1987), although the empirical evidence (e.g., Riley and McCloskey, 1996) indicates that the reality is quite benign — at least for professional workers. We hypothesize, in keeping with Olson and Primps' (1984) results, that lack of visibility is more likely to be perceived as a disadvantage by professional/technical workers than by clerical workers. And although managers may be equally (or more) concerned with career advancement as professionals, it may be expected that they themselves are already managed remotely to some extent, and therefore that telecommuting is less of a noticeable departure from the status quo for them. We further hypothesize, in view of the considerable attention paid to the "mommy track" and the "glass ceiling" for women (e.g. Schwartz, 1989; Hall, 1989) that women are more likely to be concerned about lack of visibility than men (this was found empirically by Pratt, 1984).

Another frequently-cited disadvantage of telecommuting is the social and professional isolation associated with it (although it should be noted that such isolation is primarily an issue for high-frequency telecommuting - often associated with clerical workers doing routine data entry work at home-rather than for the 1-or-2-day-a-week levels associated with much telecommuting by professional workers). Salomon and Salomon (1984, p. 20), citing an earlier study (Herzberg, et al., 1957), indicate that "[t]he social interaction aspect [of the job] was found to be more important among workers of routine duties and those holding jobs that provided little satisfaction from the work itself", whereas "[t]he social role of the workplace is of less importance in managerial and professional jobs. Workers of this type ranked achievement, advancement, and the work itself as factors that contribute most to job satisfaction". Thus, it can be hypothesized that clerical workers are more likely to be concerned about a loss of social interaction with telecommuting, whereas the other two groups may be more likely to be concerned about professional interaction. However, Shamir and Salomon (1985) suggest that workers of all types may value the social relationships of the workplace, which may negate the first part of the hypothesis (also see Duxbury, et al., 1987). 
The specific hypotheses implied by the above discussion are stated below. Further, as this study is essentially exploratory, we systematically examine all potential effects of gender and occupation on telecommuting perceptions, even when no prior hypothesis (or multiple competing hypotheses) may be apparent. All significant results (and some nonsignificant ones) are presented and discussed in the following subsection.

\section{Gender-based Hypotheses}

G1: Women are more likely than men to cite family reasons as advantages of telecommuting.

G2: Women are more likely than men to cite personal reasons as advantages of telecommuting.

G3: Women are more likely than men to perceive stress reduction as an advantage of telecommuting. G4: Women are more likely than men to see lack of management visibility as a disadvantage of telecommuting.

G5: Women are more likely than men to see the benefits of commuting as a disadvantage of telecommuting.

\section{Occupation-based Hypotheses}

01: Managers and professional workers (independent of gender) are more likely to cite work-related reasons as advantages of telecommuting.

O2: Clerical workers are more likely to perceive family reasons as advantages of telecommuting.

O3: Clerical workers are more likely to cite personal reasons as advantages of telecommuting.

04: Managers are less likely to perceive reduced stress as an advantage of telecommuting.

05: Managers and professional workers are more likely to see reduced professional interaction as a disadvantage of telecommuting.

O6: Clerical workers are more likely to see reduced social interaction as a disadvantage of telecommuting.

07: Professionals are more likely to view lack of visibility to management as a disadvantage.

\section{RESULTS}

Gender and occupation differences in perceived advantages and disadvantages of telecommuting are analyzed in two ways here: through examining the individual advantages and disadvantages cited as most important, and through analyzing the factor scores for the five advantage and four disadvantage factors. Importance ratings for the individual attributes were also examined, but the factor scores constitute composite ratings that carry essentially the same information in a more compact form. The most important advantage and disadvantage variables are binary (equal to one if the respondent chose it as most important, zero otherwise), and hence Pearson chi-square tests were performed to determine if there were significant differences in the distribution of responses by gender and occupation separately, and (where appropriate) by occupation within each gender category and/or by gender within each occupation type. T-tests were conducted to check for significant differences in the mean response values within and across groups. On the other hand, the factor scores are continuous variables, and thus analysis of variance methods were used to analyze them.

These two approaches are complementary. The most important advantage and disadvantage reported by an individual may likely be the strongest single indicators of his/her motivation to telecommute or not. On the other hand, the "most important" variables represent a forced choice: some respondents may have dutifully recorded a most important advantage even when they did not consider that advantage (or any other) particularly important in absolute terms. Further, several variables may relate to a single underlying dimension, and the choice among them of the most important variable may be somewhat arbitrary. Factor scores, on the other 
hand, capture the intensity of perception: individuals who did not consider a certain group of related advantages very important would have a low score on the factor derived from those advantages. It is just as important to understand how gender-occupation groups vary in the degree to which they value various potential characteristics of telecommuting as it is to know how they differ on what they consider the most important characteristics.

\section{Most Important Advantages}

For simplicity of exposition, we focus on the top six attributes in each of the two categories. Figure 1 portrays, for the top six advantages, the fraction of respondents in each group citing that attribute as most important. At the outset, it is important to note that the size of the male clerical worker sample is very small $(\mathrm{N}=12)$, and thus, the fraction of respondents in this group choosing a particular attribute may not be reliable.

Figure 1

Fraction of Respondents in Each Group Choosing Telecommuting Advantage as Most Important

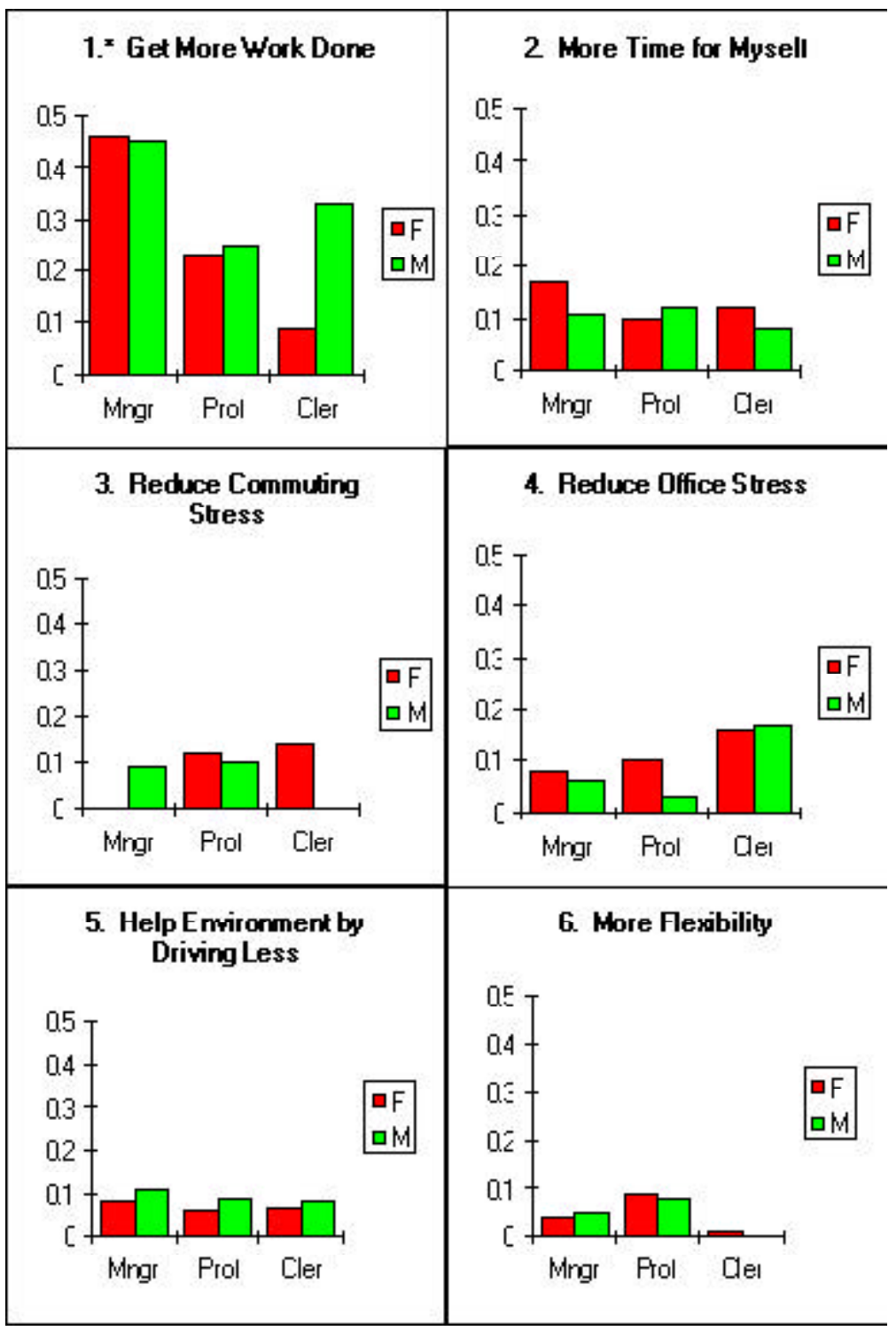


The six variables shown in Figure 1 were cited by $69 \%$ of the overall sample as being most important: get more work done (most important to $23.8 \%$ overall), more time for myself $(11.7 \%)$, reduce commuting stress $(10.8 \%)$, reduce office stress $(8.7 \%)$, help the environment by driving less $(7.9 \%)$, and more flexibility (6.0\%). None of the remaining 11 advantages were most important to more than $5.2 \%$ of the sample. Collectively, these variables indicate that stress, personal benefits, and travel/environmental issues are likely to be important drives in an individual's telecommuting preference formation.

Chi-square tests on the variable "get more work done" found a significant gender difference $(p=0.001)$, with $30 \%$ of men but only $18 \%$ of women citing it as most important. However, as shown in the figure, the percentages of men and women within each occupation group choosing it as most important were very similar. In fact, within the two job types having a significant number of male workers, chi-squared tests show no significant gender differences (manager $\mathrm{p}$-value $=0.92$; professional $\mathrm{p}$-value $=0.70$ ) This result is consistent with previous studies cited in Section 3.1.

Although there are no significant differences between gender within occupation, there are significant differences across occupations without regard to gender $(\mathrm{p}=0.000)$. Nearly half of all managers cited getting more work done as the most important advantage of telecommuting. Presumably managers are subject to many interruptions that can be more readily controlled in a telecommuting environment. Nearly a quarter of the professional/technical workers group cited this attribute as most important. Overall, the responses for this variable support hypothesis $\mathrm{O} 1$.

The second-most cited variable, "more time for myself", can be categorized as a personal benefit of telecommuting. As such, it could be hypothesized (see G2) that women would more often than men select this advantage as most important. However, chi-squared tests did not show any distinctions within gender $(\mathrm{p}=0.992)$ or occupation $(\mathrm{p}=0.973)$. "Reducing the stress of commuting" is another advantage of telecommuting that could potentially be more attractive to women (see G3). Here too, however, there were no significant differences within gender $(p=0.335)$ or occupation $(p=0.319)$ in selecting this advantage.

The next variable, "reducing office stress", was significantly more important to women than men (13\% of the women chose it versus only $4 \%$ of the men; $\mathrm{p}=0.000$ ), in support of hypothesis G3. Further, female clerical workers were more likely to choose it than females in the other two job types, indicating that this is the primary group perceiving reduced office stress to be a key advantage of telecommuting (pair-wise t-tests across occupations showed significantly different means between clerical workers and the other two groups, p-values < 0.02). Of the three job types, clerical workers may have the least control over their working conditions, and consequently, may feel more office stress. Stress was also differentially important to female professionals however; as Figure 1 shows, they were more than four times as likely as their male counterparts to cite this advantage $(p=0.002$ for chi-squared test of gender difference within the professional workers group).

For the variable "help the environment by driving less", no chi-squared or t-test showed a significant difference among occupations or gender for 0.05 , suggesting that this particular advantage is approximately equally important across the six study groups. The last variable, "more flexibility", showed significant occupation differences $(\mathrm{p}=0.006)$, with professionals $(8.5 \%$ of that group) most likely to cite it, managers next most likely (4.5\%), and clerical workers least likely (1.3\%). 
It is interesting to note that the family-related advantages of telecommuting were separately not among the top six. Two such advantages combined, however, were most important for more than $10 \%$ of the overall sample (which would have placed family issues fourth in the ranking): "spend more time with my family" $(5.1 \%)$ and "easier to handle dependent care" (5.0\%). There were no significant gender or occupation differences for the variable "spend more time with family". The dependent care variable, on the other hand, showed significant differences for both gender $(p=0.001)$ and occupation $(p=0.00001)$.

Clerical workers $(12.3 \%)$ were five and ten times as likely as professional $(2.6 \%)$ and managerial $(1.1 \%)$ workers to cite this advantage as most important, in support of $\mathrm{O} 2$ and consistent with the evidence in Table 4 that this group most often had dependents needing special care. Women (7.8\%) were four times as likely as men (1.8\%) to cite dependent care as an advantage, in support of hypothesis G1. This is especially telling since, as can be derived from Table 4, one-third more men (24\%) in the sample had children under age 6 than did women (18\%), and similar proportions of men (21\%) and women (23\%) had older children living at home. Interestingly, however, within occupation groups there were no significant gender differences, although cell sizes were generally too small to warrant emphasizing this outcome.

The difference in response patterns between the two family-related advantages of telecommuting is suggestive. It may well be the case that men and women are equally likely to see their family role in terms of spending time together, whereas women are more likely than men to see their family role in terms of caring for dependents. This finding illustrates the need to carefully define a "family" variable in this type of context.

A composite variable was created to combine the two family variables, and gender/occupation differences were tested for in the tendency to cite either variable as the most important advantage. The results for this composite variable roughly parallel those for the dependent care variable: there were moderately significant gender $(p=0.06)$ and very significant occupation $(p=0.0006)$ differences, in the same directions as before but with smaller contrasts between groups. Within occupation, there were no significant gender differences, although some cell sizes remained rather small.

Taken together, these results can be considered to offer only mixed or partial support for the hypothesis (G1) that women are more likely than men to cite family reasons as advantages of telecommuting.

\section{Most Important Disadvantages}

Turning to the most important disadvantage variables, the top six disadvantage variables shown in Figure 2 were collectively cited as most important by $84 \%$ of the overall sample: professional interaction $(22.1 \%)$, career advancement $(20.1 \%)$, social interaction (16.3\%), negative management view (9.9\%), better main office $(9.1 \%)$, and motivation $(6.2 \%)$. None of the remaining five disadvantages were most important for more than $4 \%$ of the sample. Taken together, these results suggest that workplace interaction, management visibility, and office discipline are important constraints in an individual's telecommuting preference formation.

Males (28\%) were significantly more likely than females (17\%) to report "reduced professional interaction" as the most important disadvantage of telecommuting $(\mathrm{p}=0.001)$. However, it is clear that some women also feel this disadvantage is powerful, as the highest selection percentage (42\%) of any one group came from the women managers. In terms of occupations, managers were much more likely to choose this disadvantage as most important $(\mathrm{p}=0.000)$, partially confirming hypothesis O5. Fully $39 \%$ of the manager group cited this variable (by far the most-frequently-selected disadvantage for that group), 
compared to $23 \%$ of professionals and $10 \%$ of clerical workers. Similarly, a related disadvantage of telecommuting, "reduced social interaction", also varied significantly across occupations (pooled chisquare p-value $=0.06)$, although not across genders. Interestingly, clerical $(19 \%)$ and professional $(17 \%)$ workers were about equally likely to cite this variable (t-test $\mathrm{p}=0.692)$, and both groups were significantly more likely than managers to do so (t-test p-values of 0.011 and 0.008 respectively). Thus, as seen from the data, both females and males, and both professional and clerical workers, rated social interaction equally highly, which is broadly consistent with the literature cited in Section 3.1. This supports and modifies hypothesis O6.

"Career advancement" and "negative management view" were related disadvantages collectively chosen as most important by nearly a third of the sample. Both were notably more important to women (pvalues < 0.03$)$. Women $(38 \%)$ were almost twice as likely as men $(21 \%)$ to cite one of these two variables as the most important disadvantage, corroborating hypothesis G4. Lefkowitz (1994) found that "the importance of advancement" was one of only two job-related variables that women rated higher than men. The large difference between men and women in this area seems to point to a current corporate culture that is perceived by women to be biased towards male success.

A "better main office" and "motivation", two disadvantages dealing with office discipline, were selected as most important by $15.3 \%$ of the sample. This result suggests that office discipline issues represent an important area that individuals consider in their telecommuting preference formation. However, as responses were not significantly different among groups, office discipline disadvantages are apparently valued similarly across genders and occupations.

It is interesting to note that the three variables associated with benefits of commuting (see disadvantage statements 8-10, Table 1) did not have significantly different distributions across gender-occupation groups, and in fact, collectively only accounted for $5.0 \%$ of the choices for most important disadvantage. Thus, there is no support for hypothesis G5 among the most important rankings of this sample.

\section{Advantage and Disadvantage Factor Scores}

For the gender-occupation groups in this study, a two-factor analysis of variance (ANOVA) model was used to identify, for each factor score, significant gender main effects, occupation main effects, and interaction effects. (Note the two different, but equally conventional in separate contexts, uses of the word "factor"). Testing for a gender main effect compares males and females on each factor score to determine if the mean scores differ significantly by gender. Similarly, testing for an occupation effect examines whether the mean factor scores differ across the three job types. Testing for an interaction effect shows whether any change across gender type varies by occupation type (or conversely).

Plots of the mean factor scores for telecommuting advantages and disadvantages by gender and occupation are displayed in Figures 3 and 4. Note that factor scores are standardized, so negative values simply indicate a score that is less than the overall sample mean score for that factor. All nine factors are discussed below, eight of which have at least one significant main effect at 0.05 . Although visually there may appear to be some interaction effects due to scale exaggeration, none were statistically significant. 
Figure 2

Fraction of Respondents in Each Group Choosing Telecommuting Disadvantage as Most Important

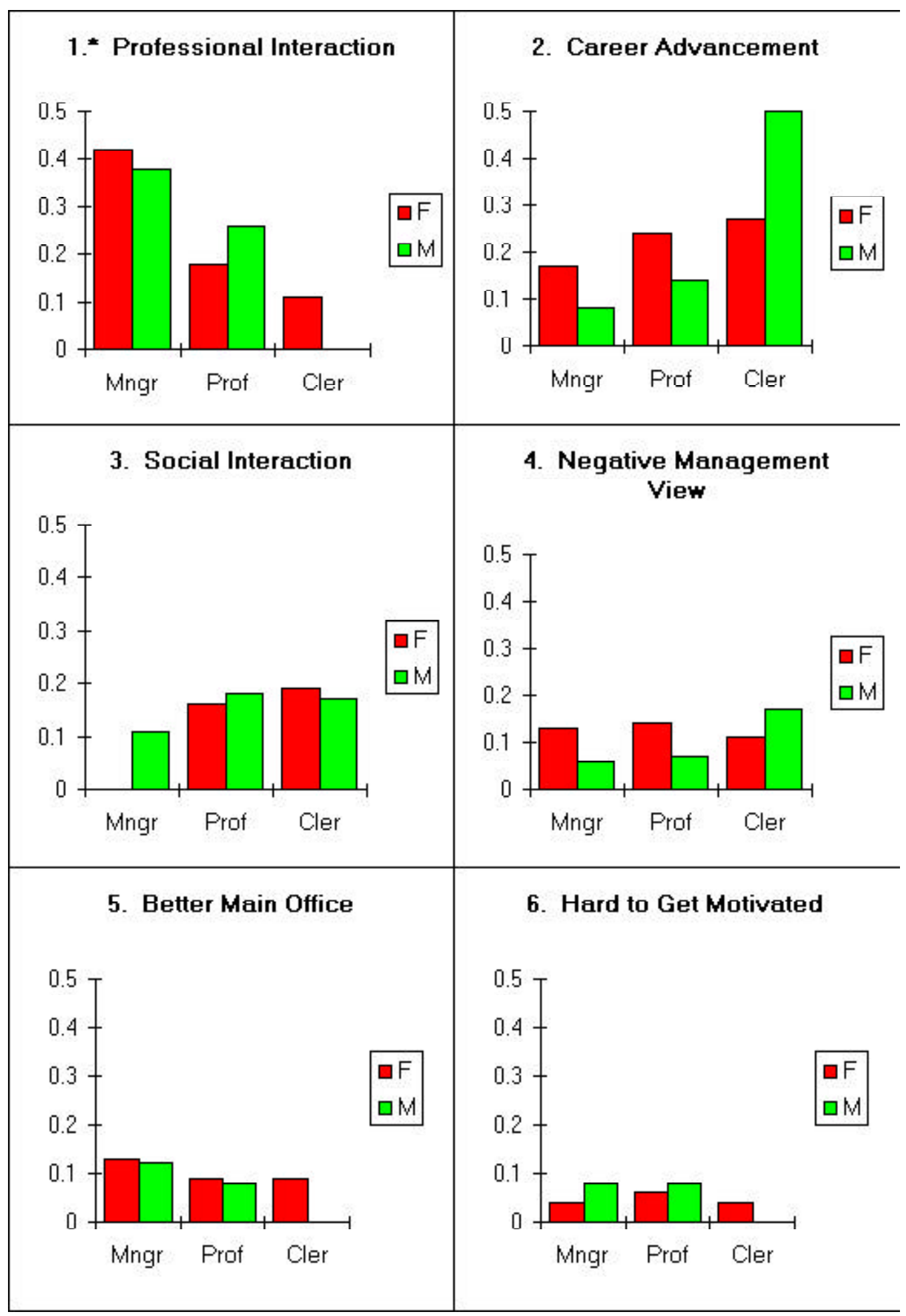




\section{Women s Travel Issues}

Proceedings from the Second National Conference

Figure 3

Plots of Mean Factor Scores for Telecommuting Advantages by Gender and Occupation

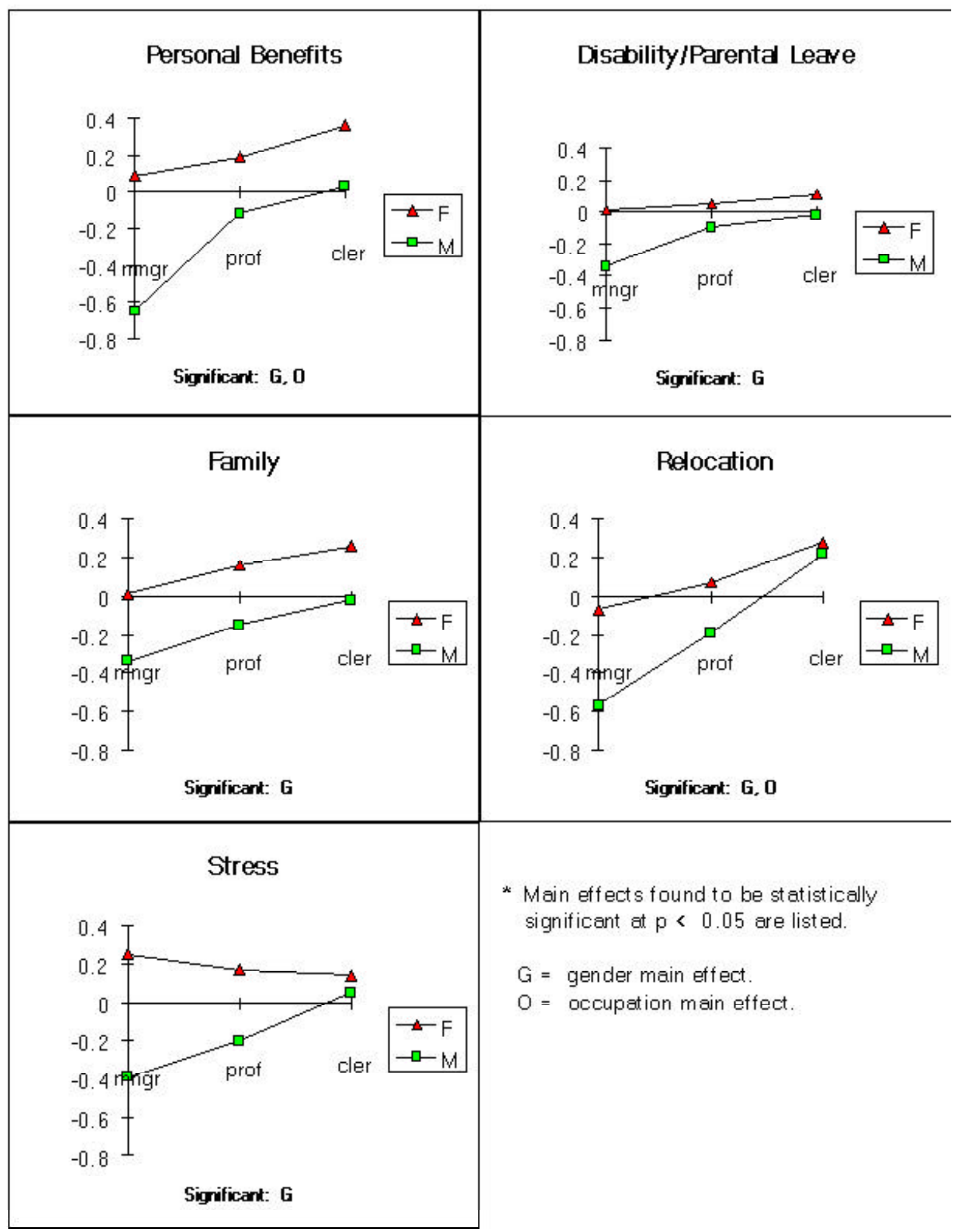


Starting with the advantages, a couple of interesting observations emerge from looking at the five factors together. First, gender effects are significant in every case: specifically, for every factor and within every occupation group, mean scores for women exceed those of men. Evidently, the potential advantages of telecommuting are on average more salient to women than to men, which helps explain why women are significantly more likely to want to telecommute and which also generally corroborates hypotheses G1-G3. Second, in general for both women and men (but more strongly for men), managers have the lowest, professional/technical workers the next highest, and clerical workers the highest mean factor scores. These occupation effects are significant for only two of the five factors, but again they are consistent with the hypothesis that telecommuting will appeal the most to those who have a great deal of stress and the least amount of control over various aspects of their lives (see O2-O4).

Turning to the personal benefits factor specifically (which, as shown in Table 1, is based on attributes such as having more time for self, and increasing independence, control, and flexibility), the ANOVA results show that both gender and occupation main effects are significant. Women rated that characteristic of telecommuting much more highly than men, and clerical workers found it much more important than the other occupations. This finding supports hypotheses G2 and O3.

Only the gender effect was significant for the two family-related factors, disability/parental leave and family. As noted, women on average rated these factors more highly than men, indicating that they perceive the ability to balance work and family as a valuable advantage of telecommuting (unambiguously supporting hypothesis G1, in contrast to the case for the most important advantage analysis). For the relocation factor, both gender and occupation effects were significant, with clerical workers placing the highest importance on the ability of telecommuting to allow them to continue to work in case of job or residential relocation. This is a natural result, since a clerical worker's job may well be most vulnerable to either type of relocation.

The last advantage factor, stress, had only a significant gender effect. Although an interaction effect is not significant, it is striking that males show a clear progression of increasing mean scores from managers (for whom reducing stress is not perceived to be an important advantage of telecommuting) to professional/technical workers, to clerical workers (in weak support of hypothesis O4). For females, on the other hand, the average scores across all three job types were quite similar. Either male managers do not experience as much stress as their female counterparts, or they do not see telecommuting as an answer to the stress they do experience. The former explanation seems more plausible.

Turning to the disadvantage factor scores, it is first observed that the systematic overall patterns noted for the advantage factors do not appear here. Gender effects are significant for only one out of the four factors, whereas occupation is significant for three. In general, the disadvantages of telecommuting appear to be somewhat more salient to professionals than to the other two job types.

The office discipline factor comprises attributes relating to problems associated with working away from the main office, such as having the right equipment, materials, and motivation. Self-motivation and self-discipline are often identified as characteristics of successful telecommuters (e.g., Katz, 1987). This factor displays a significant occupation effect, with professionals scoring more highly on this disadvantage of telecommuting than the other two groups. Professional/technical workers may have a greater need for access to sophisticated and expensive work tools (such as technical manuals and lab equipment), and their jobs may in some ways be the least routine (and therefore perhaps demanding more motivation to undertake outside the traditional office environment). 


\section{Women s Travel Issues}

Proceedings from the Second National Conference

Figure 4

Plots of Mean Factor Scores for Telecommuting Disadvantages by Gender and Occupation

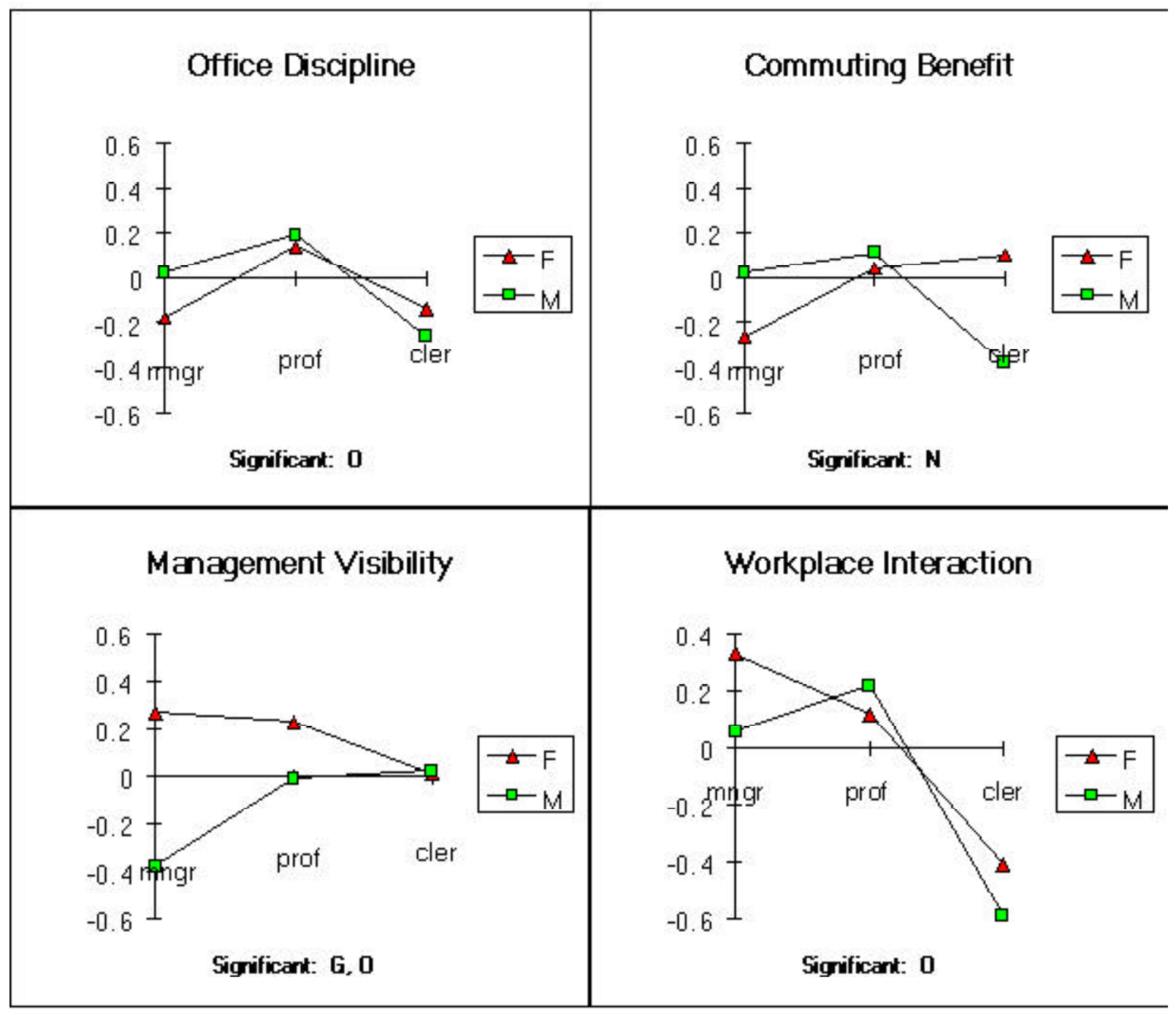

* Main effects found to be statistically significant at $p<0.05$ are listed.

$\mathrm{G}=$ gender main effect.

$\mathrm{O}=$ occupation main effect.

$N=$ no siqnificant main effect. 
Management visibility, having both gender and occupation significant effects, is the only disadvantage factor that has a significant gender effect. The mean factor scores for women were higher than those for men, showing once again that women feel more strongly that telecommuting could negatively impact their careers (hypothesis G4). As expected, the male managers had the lowest mean factor score, indicating that they are more confident that telecommuting would not hinder their job advancement opportunities. The female clerical workers had the lowest mean factor score of the female occupation groups. It may be the case that female managers and professionals are more career-oriented than female clerical workers, and thus more concerned about being viewed positively for promotions.

Workplace interaction had a significant occupation effect. Clerical workers perceived the loss of interaction at the workplace to be less important than did professionals and managers. (The fact that the factor combines both social and professional interaction makes the relationship of this result to hypotheses $\mathrm{O} 5$ and $\mathrm{O} 6$ somewhat problematic). Rather, it is the female managers who score most highly on this factor. Overall, it appears that workplace interaction is important to both professionals and managers, which is consistent with the literature (Shamir and Salomon, 1985).

The only factor without a significant effect was the telecommuting disadvantage commuting benefit. Thus, there is no support for hypothesis G5 in this sample. As we have seen here and elsewhere (Mokhtarian and Salomon, 1996c) that women have higher scores on both general stress (analyzed here and containing some aspects of commute stress) and a specific commute stress factor (derived from attitudinal statements in another section of the survey), it may be the case that the negative aspects of the commute tend to outweigh the positive aspects in women's minds.

\section{CONCLUSIONS AND RECOMMENDATIONS FOR FUTURE RESEARCH}

This study has identified numerous gender- and occupation-related differences in the way telecommuting is perceived. Most broadly, women on average rated the advantages of telecommuting more highly than men-both overall and within each occupation group. Telecommuting appears to appeal more strongly to women as a solution to problems they face, although it is worth pointing out again that telecommuting was highly desirable to the men in this sample as well (preferred by $83 \%$ of men, compared to $92 \%$ of women).

Table 5 summarizes the key findings of this study. Nearly all of the specific hypotheses formulated from the literature and from judgement were corroborated to some degree by the empirical evidence. Women were more likely than men to cite family, personal benefits, and stress reduction as advantages of telecommuting, and more likely to see the lack of visibility to management as a disadvantage. Clerical workers were more likely than managers or professionals to see the family, personal, and office stress-reduction benefits of telecommuting as important, whereas managers and professionals were more likely to cite getting more work done as the most important advantage of telecommuting. Reduced social interaction appeared to be of about equal concern to both clerical and professional/technical workers, and reduced professional interaction was of greatest concern to managers and professionals. Professionals were more likely than the other two job types to see the lack of visibility to management and the need for discipline as disadvantages. The only hypothesis not corroborated at all by the data was that women would be more likely than men to see the benefits from commuting as a disadvantage of telecommuting. 


\section{Women s Travel Issues}

Proceedings from the Second National Conference

Table 5

Summary of Results

\begin{tabular}{|c|c|}
\hline GENDER-BASED RESULTS & OUTCOME/BASIS* \\
\hline \multicolumn{2}{|l|}{ Prior Hvootheses } \\
\hline G1: Women more likelv to cite familv reasons as benefits & ves: MI (vartial). FS \\
\hline G2: Women more likelv to cite personal reasons as benefits & ves: $\mathrm{FS}$ \\
\hline G3: Women more likelv to nercerve stress reduction as a be nefit & $\begin{array}{l}\text { ves: MI (office). } \\
\text { FS (general) }\end{array}$ \\
\hline $\begin{array}{l}\text { Cr4. Wnmen more likelun th see lark nf management visihilitw as a } \\
\text { cost }\end{array}$ & wes: $\mathrm{MT} F \mathrm{FS}$ \\
\hline G5: Women more likelv to see benefits of commuting as a cost & no \\
\hline \multicolumn{2}{|l|}{ Other Gender Results } \\
\hline $\begin{array}{l}\text { Women more likelv to see kee ping same iob after relocation as a } \\
\text { benefit } \\
\text { Men more likelv to see lack of mofessional interaction as a cost }\end{array}$ & $\begin{array}{l}\text { ves: } \mathrm{FS} \\
\text { ves: } \mathrm{MI}\end{array}$ \\
\hline OCCIIPA TION_RASFD RFSIII.TS & OITTCOMF.JPASIS \\
\hline \multicolumn{2}{|l|}{ Prior Hrootheses } \\
\hline $\begin{array}{l}\text { O1: Managers and rrofessionals more likelv to cite work-related } \\
\text { reasons as benefits }\end{array}$ & $\begin{array}{l}\text { ves: MI (mgrs highest. profs } \\
\text { next) }\end{array}$ \\
\hline O2: Clerical workers more likelv to cite familv reasons as benefits & ves: MII. FS (weakbut WS) \\
\hline 03: Clerical workers more likelv to cite personal reasons as benefits & ves: $\mathrm{FS}$ \\
\hline 04: Managers less likelv to perceive reduced stress as a benefit & $\begin{array}{l}\text { some what: FS (weak but NS } \\
\text { sumport for male mers) }\end{array}$ \\
\hline $\begin{array}{l}\text { O5: Managers and professional workers more likelv to see reduced } \\
\text { professional interaction as a cost }\end{array}$ & $\begin{array}{l}\text { ves: MI (mgrs). FS (both rrof } \\
\text { and soc interaction) }\end{array}$ \\
\hline $\begin{array}{l}\text { O6: Clerical workers more likelv to see reduced social interaction as } \\
\text { acost }\end{array}$ & ves. with mrofs: MI \\
\hline $\begin{array}{l}\text { O7: Professionals more likelv to view lack of visibilitv to } \\
\text { managementas a cost }\end{array}$ & ves: FS \\
\hline \multicolumn{2}{|l|}{ Other Occuration Results } \\
\hline Clerical workers more likelv to see reduced office stress as a benefit & ves: $\mathrm{MI}$ \\
\hline $\begin{array}{l}\text { Professionals more likelv to see increased flexibilitv as most } \\
\text { immortant benefit }\end{array}$ & ves: MI \\
\hline $\begin{array}{l}\text { Clerical workers more likelv to see keening same iob after relocation } \\
\text { as a benefit }\end{array}$ & ves: FS \\
\hline $\begin{array}{l}\text { Professionals about as likelv as clerical workers to see reduced social } \\
\text { interaction as a cost }\end{array}$ & ves: $\mathrm{MI}$ \\
\hline
\end{tabular}

* $\quad \mathrm{MI}=$ most important advantage or disadvantage analysis; FS = factor score analysis; $\mathrm{NS}=$ not statistically significant. 
Two immediate extensions of this research would be useful. The first is to incorporate the effects of having children at home into the analysis. It may be that some of the gender effects seen here are actually interaction effects of gender with children. Conversely, it may be the case that some effects which do not differ significantly across gender alone may differ depending on the presence or absence of children, or on a gender-children interaction. There may be children-occupation interaction effects as well.

The second useful extension of this research is to explore gender and occupation differences in the constraints on telecommuting. Table 4 shows that while women are more likely than men to prefer telecommuting, they are equally likely actually to be telecommuting. This suggests that constraints on the ability to telecommute are operating more strongly for women than for men. Conversely, there were no occupation differences in the preference to telecommute, but significant variations in the choice of telecommuting. Thus, constraints are operating differentially for occupations as well.

Mokhtarian and Salomon (1994) and others have identified a number of external and internal constraints on the ability/desire to telecommute. External constraints can be classified as relating to awareness, the organization, and the job, whereas internal constraints are psychosocial factors. Most of the latter (e.g. personal interaction needs, lack of discipline, benefit of commuting) have already been examined here in the study of perceived disadvantages of telecommuting. Data on the external constraints have been collected in the same survey used for this paper (see, e.g., Mokhtarian and Salomon, 1996a), and it would be relatively straightforward to examine these data for occupation and gender differences.

Telecommuting has been labeled a "complex solution" - that is, "a single intervention which is intended to solve many problems" (Salomon, forthcoming). In this study we see clear evidence that telecommuting appeals to people for a variety of reasons, and further that different reasons are important to different types of people. We also see evidence, as Salomon suggests, that the perceived costs of telecommuting are different for different people. What this study alone cannot answer is how closely the perceived benefits and costs match the reality once telecommuting is tried. Such knowledge will be important to assess whether telecommuting lives up to its promise, and whether its costs are fair and equitably distributed. The answers to those questions in turn will affect forecasts of future telecommuting adoption and the development of public policy on telecommuting. Hence, the study of gender and occupation differences in a multi-employer sample containing large numbers of (1) telecommuters, (2) those who want to telecommute but are not doing so, and (3) those who do not want to telecommute, would be extremely valuable. 


\section{ACKNOWLEDGMENT}

This study was funded by the University of California Transportation Center.

\section{REFERENCES}

Bagley, Michael N. (1995) Binary and Multinomial Models of the Preference for Center-Based Telecommuting. Master's Thesis, Department of Civil and Environmental Engineering, University of California, Davis. UCD Institute of Transportation Studies Research Report UCD-ITS-RR-95-16, September.

Bielby, Denise D., and Bielby, William T. (1988) "She works hard for the money: Household responsibilities and the allocation of work effort." American Journal of Sociology 93(5), 1031-1059.

Bielby, William T., and Bielby, Denise D. (1989) "Family ties: Balancing commitments to work and family in dual earner households.” American Sociological Review 54, 776-789.

Christensen, Kathleen (1988) Women and Home-Based Work: The Unspoken Contract . Henry Holt and Co., New York.

DeSanctis, Gerardine (1984) "Attitudes toward telecommuting: Implications for work-at-home programs." Information and Management 7, 133-139.

DuBrin, Andrew J. (1991) "Comparison of the job satisfaction and productivity of telecommuters versus in-house employees: A research note on work in progress." Psychological Reports 68, 1223-1234.

Duxbury, Linda E., Higgins, Chris A., and Irving, Ric H. (1987) "Attitudes of managers and employees to telecommuting." INFOR 25(3), 273-285.

Feuer, Dale (1988) "Making the leap from supervision to management." Training, December, 62-67.

Hall, Douglas T. (1989) “Moving beyond the 'Mommy Track': An organization change approach.” Personnel (December), 23-29.

Hartman, Richard I., Stoner, Charles R., and Arora, Raj (1991) "An investigation of selected variables affecting telecommuting productivity and satisfaction." Journal of Business and Psychology, 6(2), 207-225.

Herzberg, F., Mausner, B., and Peterson, R.D. (1957) Job Attitudes: Review of Research and Opinion . Pittsburgh, PA: Psychological Service of Pittsburgh.

Katz, Adolph I. (1987) "The management, control, and evaluation of a telecommuting project: A case study." Information and Management 13, 179-190.

Lefkowitz, Joel (1994) "Sex-related differences in job attitudes and dispositional variables: Now you see them, ..." Academy of Management Journal 37(2), 323-349. 
Mannering, Jill S. and Mokhtarian, Patricia L. (1995) "Modeling the choice of telecommuting frequency in California: An exploratory analysis." Technological Forecasting and Social Change 49(1), 49-73.

Mokhtarian, Patricia L., and Salomon, Ilan (1994) "Modeling the choice of telecommuting: Setting the context." Environment and Planning A, 26(5), 749-766.

Mokhtarian, Patricia L., and Salomon, Ilan (1996a) "Modeling the choice of telecommuting 2: A case of the preferred impossible alternative." Forthcoming Environment and Planning A.

Mokhtarian, Patricia L., and Salomon, Ilan (1996b) "Modeling the choice of telecommuting 3: Identifying the choice set and estimating binary choice models for technology-based alternatives." Forthcoming Environment and Planning A.

Mokhtarian, Patricia L., and Salomon, Ilan (1996c) "Modeling the desire to telecommute: The importance of attitudinal factors in behavioral models." Forthcoming Transportation Research A.

Newman, S. (1989) “ Telecommuters bring the office home.” Management Review 78(12), 41-42.

Olson, Margrethe H. and Primps, Sophia B. (1984) "Working at home with computers: Work and nonwork issues.” Journal of Social Issues 40(3), 97-112.

Pazy, Asya, Salomon, Ilan, and Pintzov, Tovi (1996) “The impacts of women's careers on their commuting behavior: A case study of Israeli Computer Professionals." Transportation Research A 30A(4), 269-286.

Pratt, Joanne H. (1984) "Home teleworking: A study of its pioneers." Technological Forecasting and Social Change 25, 1-14.

Riley, Francine and McCloskey, Donna Weaver (1996) "GTE's experience with telecommuting: Help ing people balance work and family." Proceedings of the 1996 ACM SIGCPR/SIGMIS Confer ence, April 11-13, Denver, Colorado, 85-93.

Salomon, Ilan (forthcoming) "Social forecasting and technological change: The case of telecommuting as travel substitute." Transportation Research C.

Salomon, Ilan and Salomon, Meira (1984) “Telecommuting: The employee's perspective.” Technologi cal Forecasting and Social Change 25(1), 15-28.

Schwartz, Felice (1989) "Management women and the new facts of life." Harvard Business Review (January-February), 65-76.

Shamir, Boas, and Salomon, Ilan (1985) "Work-at-home and the quality of working life." Academy of Management Review 10(3), 455-464.

Tingey, Holly, Kiger, Gary, and Riley, Pamela J. (1996) “Juggling multiple roles: Perceptions of working mothers." The Social Science Journal 33(2), 183-191. 